\title{
Erratum to: Platelet-rich plasma releasate promotes angiogenesis in vitro and in vivo
}

\author{
Natsuko Kakudo • Naoki Morimoto • \\ Satoshi Kushida $\cdot$ Takeshi Ogawa $\cdot$ Kenji Kusumoto
}

Published online: 18 June 2014

(C) The Japanese Society for Clinical Molecular Morphology 2014

Erratum to: Med Mol Morphol (2014) 47:83-89

DOI 10.1007/s00795-013-0045-9

In the original publication of the article, Fig. $2 \mathrm{a}$ was published incorrectly. The correct figure is given below.

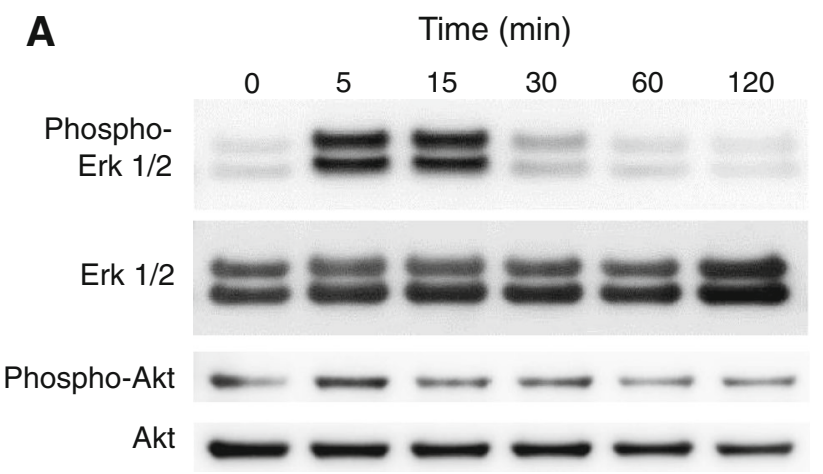

The online version of the original article can be found under doi:10.1007/s00795-013-0045-9.

N. Kakudo $(\bowtie) \cdot$ N. Morimoto $\cdot$ S. Kushida $\cdot$ T. Ogawa .

K. Kusumoto

Department of Plastic and Reconstructive Surgery,

Kansai Medical University, 2-3-1 Shinmachi, Hirakata,

Osaka 573-1191, Japan

e-mail: kakudon@hirakata.kmu.ac.jp 